\title{
Other Computer and Mathematical Workers
}

National Cancer Institute

\section{Source}

National Cancer Institute. Other Computer and Mathematical Workers. NCI Thesaurus.

Code C122539.

Computer and mathematical workers not specifically identified elsewhere. 